\title{
Analytical hierarchy process (AHP) approach to the selection of heritage building element
}

\author{
Siti Nor Fatimah Zuraidi ${ }^{1}$, Mohammad Ashraf Abdul Rahman ${ }^{2}$, Zainal Abidin Akasah ${ }^{3}$ \\ ${ }^{1,2}$ Facutly of Engineering Technology, Universiti Tun Hussein Onn Malaysia, 84600 Muar Johor, \\ Malaysia \\ ${ }^{3}$ Facutly of Civil \& Environmental Engineering, Universiti Tun Hussein Onn Malaysia, 86400 Batu \\ Pahat Johor, Malaysia
}

\begin{abstract}
In order to bring the reduction of damage and defect of heritage buildings, the management needs to use an suitable methodology approach for the element heritage building. The goal of this paper is to make the selection of criteria and attribute by using the Analytical Hierarchy Process (AHP) for heritage building. The selection of criteria and attributes for heritage building are divided into three criteria which are building the structure, building fabric, and building service. By pairwise comparison matrix, the process of selection for criteria and attribute to to enable possible improvements. This finding has shown that all element criteria and attributes in heritage building are important with their function.
\end{abstract}

\section{Introduction and literature review}

The conservation of heritage buildings was initiated by the government and the private sector in Malaysia [1]. The establishment of the National Heritage Department in 2006 has shown the government's efforts to appreciate heritage buildings in Malaysia. The Department will ensure that each requirement in the National Heritage Act 2005 will be complied with by the respective Authorities. In addition, the listing of George Town and Malacca as a UNESCO Heritage Site on July 7, 2008 to make Malaysia a country to promote heritage tourism [2]. Listing under the UNESCO heritage site will be supported by relevant stakeholders including building owners, technical professionals and competent person to ensure heritage conservation efforts in Malaysia to be successful. To align demand and capacity building heritage, the management should adopt appropriate methodological approach to the planning process that reflects the essence of heritage buildings [4].

In general, element processes are very complex for heritage buildings. Need to consider many different factors, such as building use, structural resilience, building components, building condition assessments, finance, etc. [5]. The perspective of time in the design of heritage buildings, it is clear that the element in which a building is expected to operate for a relatively short time, and uncertainty increases with time [6]. Strategic planning is the basis for closing the gap between the increasing resource flexibility and uncertainty in the growth of the damage. Considering all the above, this study must make decisions related to the elements of buildings criteria [7]. 
The goal of this paper is to solve the selection of criteria and attribute of the heritage building by using Analytical Hierarchy Process AHP. The type of building and utilities should be chosen from the designated heritage building. Hence, that many of the elements in a heritage building, the selection criteria to determine is required. Thus, this study has chosen AHP to be used for selecting each element appropriate for the heritage building. Most studies, where AHP has been successfully used in selecting criteria and attributes for their respective studies. Element selection is a process related to this building. Therefore, this study has chosen to use of AHP is reasonable. In addition, the AHP approach used for rational and logical to understand, and also the process of calculation is quite simple This study analyzes the comparison of each criterion and attribute to get the priority value and eigenvector.

\section{Building element selection by using the AHP}

The Analytical Hierarchy Process (AHP) was introduced and developed [8]. AHP is a multi-criteria decision-making approach, which divides the issue into an issue hierarchy, which should be considered at work. This methodology considers a set of selected criteria and attributes in which the best solution is to determine the weight of the criteria and attributes. It should be noted that AHP uses quantitative and qualitative data. AHP is a theory by comparing pairs of measurements. Pairwise comparison methods are used to compare the criteria and attributes and determine their importance to each other. Comparisons were made using a scale of absolute judgment that represents a measure of control over the other elements with respect to a given attribute.

The defects index method suggests 37 elements to be assessed, where some elements might be entirely cultural based [9]. The elements used in Portugal, are not suitable for use in Malaysia because of the different architectural features and design of building structures are not the same as in Malaysia. Thus, for this study, the building element review has been done to select the important building element that will be utilized in this study. In total, 17 building elements have been identified from the previous studies [5]. All 17 buildings element was divided into 3 group such as building structure, building fabric, and building service. Apart from building elements identified by Pedro, 13 building elements have been added in this study [9].

The selection of element building is an important step in this study to obtain the right data from the right source. To consider the decision-making issue, AHP is used for the selection of the appropriate heritage building elements. Hierarchical structures need to be developed in a natural way by setting goals and defining criteria and attributes. The first hierarchical rank, the goal of the study is to determine the element in the heritage building. In the second stage, there are three proposed criteria to contribute to the goal. It should be noted that criteria are selected from the building's perspective. These criteria are named as building structures, building fabrics, and building services. Finally, the third stage includes different building elements that are chosen to be attributes. These attributes include foundations, columns, beams, truss, ladders, ceilings, floors, roofs, windows, doors, internal and external walls, arches, electricity, air condition, fire protection and hygiene. These elements are important in the context of heritage buildings.

\section{Method of analysis}

The Analytical Hierarchy Process is a flexible model that provides individuals or groups opportunities to construct ideas and define problems by making their own assumptions and obtaining desired solutions from them. 
The advantages of this PHA are its ability to deal with complex or fractional situations where statistical information data from the problems encountered is minimal. The data are only qualitative based on perception, experience or intuition. Thus, the problem can be perceived and observed but the completeness of numerical data is not supportable to quantitatively modeled.

In order to achieve the goal, introduces the fundamental scale, which indicates the intensity of importance on an absolute scale. The hierarchy, pairwise comparisons are carried out. In the pairwise comparison calculation procedure, each criterion is compared to each other consistently by utilizing a clear comparison scale. Saaty make use a scale of $(1,3,5,7,9)$ for the comparison of one criterion with another crietria [10]. Each level of the existing hierarchy is carried out in pairs comparisons, so that the interests or preferences of one criterion with the other criteria that exist in all charts will be known. In this way it will be known the role of each criterion that is the object of the research conducted.

The calculation process is a matrix calculation. In the calculation process, the comparison values, eigenvector and level of consistency are obtained. The calculation stages are as follows: pairwise comparative matrix of corresponding to the attributes required by the judgment numerical and its elements meet the nature of exchange, which means if the activity has a number of non zero assigned to it when compared to the activity $y$, then $j$ has the reciprocal when compared with $i$ ( aji $i /$ a $i j)$. Once the matrix is built, it is possible to calculate the priority vector [9.10]. Priority of pairwise comparisons can be calculated in various ways using eigenvector method, the geometric average method or arithmetic average method. The priorities of the elements can be estimated by finding the principal eigenvector $w$ of matrix $A, A W={ }^{\lambda_{\text {inax }}} W$, where ${ }^{\lambda_{\text {inax }}}$ is a maximum eigenvalue of the matrix $A$ [10]. The priority of the elements can be estimated by finding the main eigenvector w of matrix $A, A W=W$, where the maximum eigenvector of matrix $A$ [10]. When the normalized of vector $W$, it becomes the priority vector of elements from one level to the upper level element. Although comparative matrixs involved in the decision-making process, it is necessary to evaluate consistency by computing the consistency ratio $(C R)$ as a Consistency Index $(C I)$ and Random Index $(R I)$ ratio. Inconsistency is acceptable and reliable results can be expected from AHP if $C R<0.1$. The consistency index is calculated as $\left(\lambda_{\max }-\mathrm{n}\right) /(\mathrm{n}-1)$.

\section{Development of case studies}

For this study, by analyzing the data selection heritage building elements, criteria and attributes have been set as shown in Figure 1.

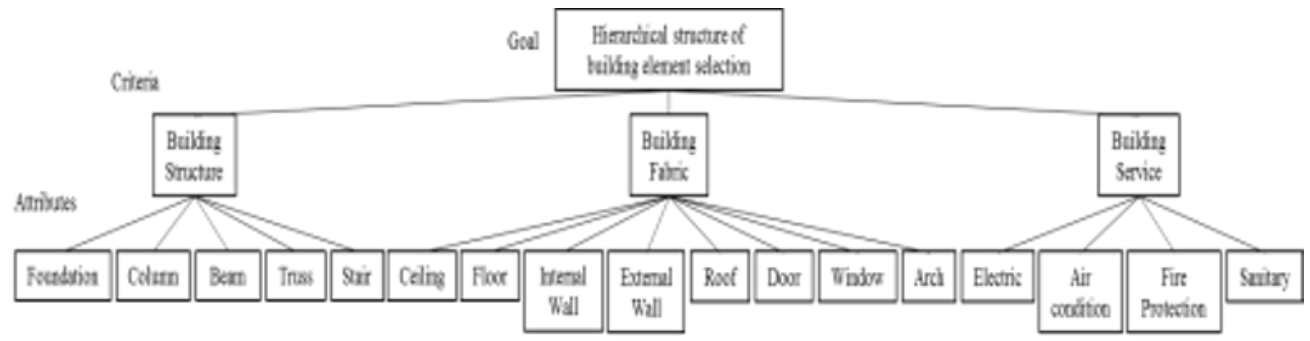

Fig. 1. Hierarchical structure of building element selection.

The selection of criteria and attributes for element building condition of heritage building are divided into three criteria which are building structure, building fabric, and building service. The structured criteria of this building consist of the main components of a building 
such as foundation, column, beam, truss, and stair. While building fabric criteria is the condition of the building component that can be seen after entering a building space such as a ceiling, internal walls, external walls, floor, roof, door, window, and arch. Finally, the attributes of building services comprise electricity, air conditioning, fire protection and sanitary.

This process produces the element weight on goal achievement, so the highest weighted element has the priority of handling. The first step at this stage is to compile paired comparisons that are transformed into matrix form so that this matrix is called a paired comparison matrix. After the problem is decomposition, then there are two stages of assessment or comparing between elements for example comparison between criteria and comparison between options for each criterion. Comparison between criteria is intended to determine the weight for each criterion. Other than that, a comparison between options for each criterion is intended to see the weight of an option for a criterion. In other words, this assessment is intended to see how important an option is to be seen from each criterion.

\subsection{AHP manual calculation for the selection process}

After providing a comparison of paired comparisons and calculating relative preferences, the final decision structure of the AHP model is to evaluate the criteria and attribute of the element in the heritage building. The finding was analysis using AHP manual calculation and set of weightage for each criterion and attributes was obtained. There is 7 step by using AHP calculation. The example of calculation shown below. Table 1 shows the pairwise comparison of all criteria and specified for each step in the matrix as follows:

Table 1. Pairwise comparison matrix of criteria.

\begin{tabular}{lccc}
\hline Criteria & Building Structure & Building Fabric & Building Service \\
\hline Building Structure & 1 & 1 & 5 \\
Building Fabric & 1 & 1 & 3 \\
Building Service & $1 / 5$ & $1 / 3$ & 1 \\
\hline
\end{tabular}

\section{Step 1.}

Change matrix to the decimal number:

$\left[\begin{array}{lll}1.000 & 1.000 & 5.000 \\ 1.000 & 1.000 & 3.000 \\ 0.200 & 0.333 & 1.000\end{array}\right]$

Step 2.

Quadratic this matrix above:

Iteration 1

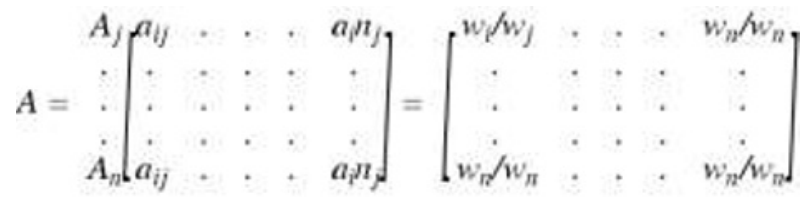

$\frac{w_{i}}{w_{j}}=a_{i j}(i, j=1,2, \ldots, n)$ 
$w_{i}=$ input value in row

$w_{j}$ inpous valse in colum

$$
\begin{aligned}
& A=\left[\begin{array}{lll}
1.000 & 1.000 & 5.000 \\
1.000 & 1.000 & 3.000 \\
0.200 & 0.333 & 1.000
\end{array}\right] \\
& A=\left[\begin{array}{lll}
1.000 & 1.000 & 5.000 \\
1.000 & 1.000 & 3.000 \\
0.200 & 0.333 & 1.000
\end{array}\right] \times\left[\begin{array}{lll}
1.000 & 1.000 & 5.000 \\
1.000 & 1.000 & 3.000 \\
0.200 & 0.333 & 1.000
\end{array}\right] \\
& \left.w_{i}=a_{i j} w_{j(i j}=1,2, \ldots . i\right) \\
& w_{i}=\text { average fran } a_{i j} w_{n} \\
& w_{11}=(1.000)^{2}+(1.000)^{2}+(5.000 \times 0.200)=3.000 \\
& w_{12}=(1.000)^{2}+(1.000)^{2}+(5.000 \times 0.333)=3.665 \\
& w_{13}=(1.000 \times 5.000)+(1.000 \times 3.000)+(5.000 \times 1.000)=13.000 \\
& w_{21}=(1.000)^{2}+(1.000)^{2}+(3.000 \times 0.200)=2.600 \\
& w_{22}=(1.000)^{2}+(1.000)^{2}+(3.000 \times 0.333)=2.999 \\
& w_{23}=(1.000 \times 5.000)+(1.000 \times 3.000)+(3.000 \times 1.000)=11.000 \\
& w_{31}=(0.200 \times 1.000)+(0.333 \times 1.000)+(1.000 \times 0.200)=0.733 \\
& w_{32}=(0.200 \times 1.000)+(0.333 \times 1.000)+(1.000 \times 0.333)=0.866 \\
& w_{33}=(0.200 \times 5.000)+(0.333 \times 3.000)+(1.000)^{2}=2.999 \\
& A=\left[\begin{array}{lll}
3.000 & 3.665 & 13.000 \\
2.600 & 2.999 & 11.000 \\
0.733 & 0.866 & 2.999
\end{array}\right]
\end{aligned}
$$

\begin{tabular}{|c|c|c|c|}
\hline & Normal Value & $\underline{\text { Total Row }}$ & Priority vector \\
\hline 3.000 & $3.665 \quad 13.0001$ & 19,665 & 0.181 \\
\hline 2.600 & $2.999 \quad 11.000$ & 16.599 & 0.406 \\
\hline 0.133 & $\left.\begin{array}{ll}0.866 & 2.999\end{array}\right]$ & 1.598 & 0.113 \\
\hline \multicolumn{2}{|r|}{ Total } & 40.862 & 1.000 \\
\hline
\end{tabular}

Step 3.

Quadratic this matrix below :

Iteration 2

$$
\begin{aligned}
& A=\left[\begin{array}{lll}
3.000 & 3.665 & 13.000 \\
2.600 & 2.999 & 11.000 \\
0.733 & 0.866 & 2.999
\end{array}\right] \\
& A=\left[\begin{array}{lll}
3.000 & 3.665 & 13.000 \\
2.600 & 2.999 & 11.000 \\
0.733 & 0.866 & 2.999
\end{array}\right] \times\left[\begin{array}{lll}
3.000 & 3.665 & 13.000 \\
2.600 & 2.999 & 11.000 \\
0.733 & 0.866 & 2.999
\end{array}\right] \\
& w_{11}=(3.000)^{2}+(3.665 \times 2.600)+(13.000 \times 0.733)=28.058 \\
& w_{12}=(3.000 \times 3.665)+(3.665 \times 2.999)+(13.000 \times 0.866)=33.244 \\
& w_{13}=(3.000 \times 13.000)+(3.665 \times 11.000)+(13.000 \times 2.999)=118.302 \\
& w_{21}=(2.600 \times 3.000)+(2.999 \times 2.600)+(11.000 \times 0.733)=23.660 \\
& w_{22}=(2.600 \times 3.665)+(2.999)^{2}+(11.000 \times 0.866)=28.049 \\
& w_{23}=(2.600 \times 13.000)+(2.999 \times 11.000)+(11.000 \times 2.999)=99.778 \\
& w_{31}=(0.733 \times 3.000)+(0.866 \times 2.600)+(2.999 \times 0.733)=6.649
\end{aligned}
$$




$$
\begin{aligned}
& w_{32}=(0.733 \times 3.665)+(0.866 \times 2.999)+(2.999 \times 0.866)=7.881 \\
& w_{33}=(0.733 \times 13.000)+(0.866 \times 11.000)+(2.999)^{2}=28.049 \\
& A=\left[\begin{array}{ccc}
28.058 & 33.211 & 118.302 \\
23.660 & 28.049 & 99.778 \\
6.619 & 7.881 & 28.019
\end{array}\right]
\end{aligned}
$$

\begin{tabular}{|c|c|c|c|}
\hline \multicolumn{2}{|r|}{ Normal value } & Total Row & $\underline{\text { Priority vector }}$ \\
\hline 28.058 & $\overline{33.211 \quad 118.302}$ & 179.609 & 0.181 \\
\hline 23.660 & 99.778 & 151.487 & 0.405 \\
\hline 6.619 & $28.019]$ & $12.5 / 9$ & 0.111 \\
\hline \multicolumn{2}{|r|}{ Total } & 373.670 & 1.000 \\
\hline
\end{tabular}

\section{Step 4.}

Difference of Iteratio 1 with Iteratio 2:

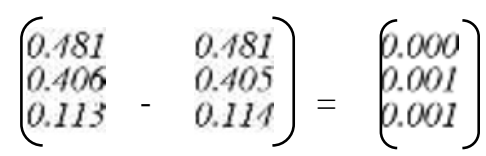

\section{Step 5.}

Calculation of maximum Eigenvalue $\left(\lambda_{\operatorname{mxz}}\right):$

$$
\begin{gathered}
V A=a_{i j x} V P \text { with } V A=\left(V_{a i}\right) \\
V B-v_{A} \text { with } V B=\left(V_{b i j}\right) \\
V B_{\text {i for } \mathbf{I}=1,2, \ldots, n} \\
V_{A}=\left(\frac{(1.000 \times 0.481)+(1.000 \times 0.405)+(5.000 \times 0.114)}{0.481}\right)=3.027 \\
V_{B}=\left(\frac{(1.000 \times 0.481)+(1.000 \times 0.405)+(3.000 \times 0.114)}{0.405}\right)=3.032 \\
V_{C}=\left(\frac{(0.200 \times 0.481)+(0.333 \times 0.405)+(1.000 \times 0.114)}{0.114}\right)=3.026 \\
\lambda_{\text {max }}-{ }_{n}^{j}{ }_{n}^{2} a_{i j} \\
\lambda_{\text {max }}=\frac{(3.027+3.032+3.026)}{3} \\
\lambda_{\text {max }}=\frac{3.028}{3}
\end{gathered}
$$

\section{Step 6.}

Calculation of consistency index $(C I)$ 


$$
\begin{aligned}
& C I-\left(\begin{array}{c}
j_{n+2}-n \\
6 r-15
\end{array}\right) \\
& C I=\left(\begin{array}{c}
3.0283 \\
(3-1)
\end{array}\right) \\
& C I-0.019
\end{aligned}
$$

\section{Step 7.}

Calculation consistency ratio $(C R)$. Random Inconsistency Index (RI) for small problems $(n=1,2,3 \ldots 10)$ is given in Table 2 .

Table 2. Random Inconsistency Index $(R I)$ for $n=1,2 \ldots 10$.

\begin{tabular}{lcccccccccc}
\hline $\boldsymbol{n}$ & 1 & 2 & 3 & 4 & 5 & 6 & 7 & 8 & 9 & 10 \\
\hline $\boldsymbol{R} \boldsymbol{I}$ & 0.00 & 0.00 & 0.58 & 0.90 & 1.12 & 1.24 & 1.32 & 1.41 & 1.45 & 1.49 \\
\hline
\end{tabular}

$$
\begin{gathered}
C R=\left(\frac{a}{n}\right) \\
C R\left(\begin{array}{c}
0.011 \\
0.58
\end{array}\right) \\
C R-0.021 \leq 0.1 \approx \text { Conssistent }
\end{gathered}
$$

\subsection{Result and discussion analysis}

The matrix of pairwise comparisons of the criteria shown in Table 3, along with the priority vector. The vector of priorities is the principal eigenvector of the matrix, therefore priorities are calculated from pairwise comparisons using AHP manual calculation with eigenvector method. Based on the equation, according to Eq. (1) to (5), and the hierarchical structure of the criteria in Figure 1. The highest priority a given to building structure with $48.1 \%$, building fabric with $40.5 \%$ and building service with $11.4 \%$ of the effect from each of them. The consistency ratio $(C R)$ indicates an acceptable level of inconsistency.

Table 3. Pairwise comparison matrix for the first level.

\begin{tabular}{lcccc}
\hline Criteria & $\begin{array}{c}\text { Building } \\
\text { Structure }\end{array}$ & $\begin{array}{c}\text { Building } \\
\text { Fabric }\end{array}$ & $\begin{array}{c}\text { Building } \\
\text { Service }\end{array}$ & $\begin{array}{c}\text { Priority } \\
\text { Vector }\end{array}$ \\
\hline Building Structure & 1.000 & 1.000 & 5.000 & 0.481 \\
Building Fabric & 1.000 & 1.000 & 3.000 & 0.405 \\
Building Service & 0.200 & 0.333 & 1.000 & 0.114 \\
\hline
\end{tabular}

$\lambda_{\max }=3.028 \quad C I=0.014 \quad C R=0.024 \leq 0.1 \approx$ Consistent

Same process to calculate the priority and eigenvector for all attributes. Changing the value of the importance of building structure which is attribute foundation over a column, column over beam, beam over the truss, truss over stair and stair over foundation, results in switching the position and changed. Table 4 shows the priority vector for each pairwise comparison matrix of the building structure. The result of comparisons attributes of the building structure shown that foundation has the highest priority with $45.8 \%$ with respect to the building structure. While the other attribute show, a column with $22.1 \%$, beam with $20.7 \%$, truss with $7.6 \%$ and the lowest is stair with $3.9 \%$. All attribute is influence from each of them. The consistency ratio $(C R)$ indicates an acceptable level of inconsistency. The ranking of attributes is as follows: foundation, column, beam, truss, and stair. 
Table 4. The pairwise comparison for each attributes with respect to the building structure.

\begin{tabular}{lcccccc}
\hline Building Structure & Foundation & Column & Beam & Truss & Stair & Priority Vector \\
\hline Foundation & 1.000 & 3.000 & 3.000 & 5.000 & 7.000 & 0.458 \\
Column & 0.333 & 1.000 & 1.000 & 5.000 & 5.000 & 0.221 \\
Beam & 0.333 & 1.000 & 1.000 & 3.000 & 7.000 & 0.207 \\
Truss & 0.200 & 0.200 & 0.333 & 1.000 & 3.000 & 0.076 \\
Stair & 0.143 & 0.200 & 0.143 & 0.333 & 1.000 & 0.039 \\
\hline
\end{tabular}

$\lambda_{\max }=5.227 \quad C I=0.057 \quad C R=0.051 \leq 0.1 \approx$ Consistent

While Table 5 shows the matrix of comparisons of the building fabric with respect to the criteria and attribute. The finding has shown that floor has the highest priority with $31.7 \%$ with respect to building fabric. However, that rank of attributes is quite sensitive to changes in the importance of interior wall over the external wall. The medium priorities are an internal wall with $18.8 \%$, the external wall with $18.4 \%$, and roof with $12.2 \%$ and the lowest is a ceiling with $8.7 \%$, door with $5.0 \%$, window with $3.1 \%$ and the lowest is arch with $2.1 \%$. All attribute is influence from each of them. The consistency ratio $(C R)$ indicates an acceptable level of inconsistency. The ranking of attributes is as follows: Floor, interior wall, external wall, roof, ceiling, door, window, and arch.

Table 5. The pairwise comparison for each attributes with respect to building fabric.

\begin{tabular}{lccccccccc}
\hline $\begin{array}{l}\text { Building } \\
\text { Fabric }\end{array}$ & Ceiling & Floor & $\begin{array}{c}\text { Internal } \\
\text { Wall }\end{array}$ & $\begin{array}{c}\text { External } \\
\text { Wall }\end{array}$ & Roof & Door & Window & Arch & $\begin{array}{c}\text { Priority } \\
\text { Vector }\end{array}$ \\
\hline Ceiling & 1.000 & 1.000 & 1.000 & 1.000 & 3.000 & 3.000 & 5.000 & 5.000 & 0.087 \\
Floor & 1.000 & 1.000 & 3.000 & 3.000 & 3.000 & 7.000 & 7.000 & 7.000 & 0.317 \\
Internal & 1.000 & 0.333 & 1.000 & 1.000 & 3.000 & 5.000 & 5.000 & 7.000 & 0.188 \\
Wall & & & & & & & & & \\
External & 1.000 & 0.333 & 1.000 & 1.000 & 3.000 & 5.000 & 5.000 & 5.000 & 0.184 \\
Wall & & & & & & & & & \\
Roof & 0.333 & 0.333 & 0.333 & 0.333 & 1.000 & 3.000 & 5.000 & 7.000 & 0.121 \\
Door & 0.333 & 0.143 & 0.200 & 0.200 & 0.333 & 1.000 & 3.000 & 5.000 & 0.050 \\
Window & 0.200 & 0.143 & 0.200 & 0.200 & 0.200 & 0.333 & 1.000 & 3.000 & 0.031 \\
Arch & 0.200 & 0.143 & 0.143 & 0.200 & 0.143 & 0.200 & 0.333 & 1.000 & 0.021 \\
\hline
\end{tabular}

$\lambda_{\max }=8.779 \quad C I=0.111$

$C R=0.079 \leq 0.1 \approx$ Contsistent

Table 6 shows the matrix of comparisons of the building service with respect to the criteria and attribute. It can be seen that electric have the highest priority with $52.5 \%$. The medium priorities are air condition with $27.9 \%$ and fire protection with $13.9 \%$ and the lowest is sanitary with $5.7 \%$. The value of these priority vector is extremely high for small values of importance from 0.525 to 0.057 , meaning that the results show attribute electric more importance than other attributes. The consistency ratio $(C R)$ indicates an acceptable level of inconsistency. The ranking of attributes is as follows: electric, air condition, fire protection and sanitary.

Table 6. The pairwise comparison for each attributes with respect to building service.

\begin{tabular}{lccccc}
\hline $\begin{array}{l}\text { Building } \\
\text { Service }\end{array}$ & Electric & Air Condition & $\begin{array}{c}\text { Fire } \\
\text { Protection }\end{array}$ & Sanitary & Priority Vector \\
\hline Electric & 1.000 & 3.000 & 3.000 & 7.000 & 0.525 \\
Air Condition & 0.333 & 1.000 & 3.000 & 5.000 & 0.279 \\
Fire Protection & 0.333 & 0.333 & 1.000 & 3.000 & 0.139 \\
Sanitary & 0.143 & 0.200 & 0.333 & 1.000 & 0.057 \\
\hline$\lambda_{\max }=4.140$ & & $C I=0.047$ & $C R=0.052 \leq 0.1 \approx$ Contsistent
\end{tabular}


After reaching the solution, the sensitivity of solution (rank of priority vectors) and a consistency ratio with respect to different judgment in comparison matrix for the first level are to analyze. By varying one element in the pairwise matrix from 1/9 to 9 (according to Saaty's scale) while keeping the other constant, consistency ratio is calculated as well as final priority vector that defines rank of attributes.

Figure 2 shows the experiment carried out that sensitivity of $C I$ and $C R$ is significant to the changes of different judgment in comparison matrix for the attribute elements, while solution is almost significant to these changes. In three criteria, there is have a difference in rank of attributes. The value of the importance of building structure over building fabric, building fabric over building service, building service over building structure has no influence on the solution. The importance is varied from building structure to building service are consider and show the results where all criteria $C R$ is consistent and acceptable.

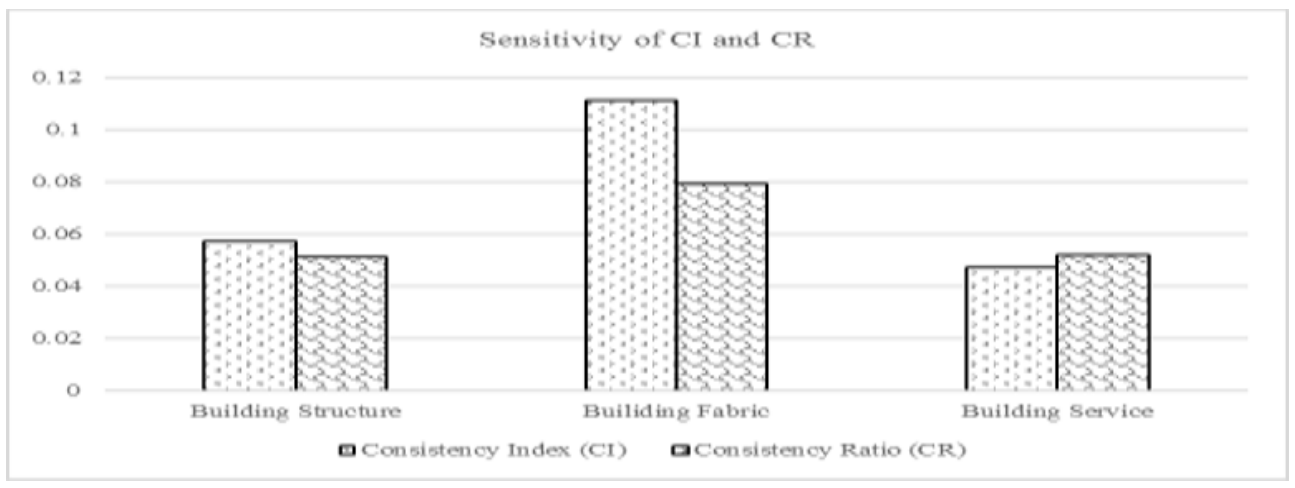

Fig. 2. Changes in $C I$ and $C R$ depending on the importance of attribute element.

By using the AHP to make a selection for the element of building. The summarize of result for all element shown in Table 7. All priority weightage for the criteria and attributes as below. The consistency ratio $(C R)$ in all pairwise comparisons matrix is acceptable (it is less than 0.10 or $10 \%$ ), which confirm the validity of the selection is obtained.

Table 7. Summarize of priority weightage by criteria and attributes.

\begin{tabular}{lllc}
\hline Criteria & Priority Weightage & \multicolumn{1}{c}{ Attribute } & Priority Weightage \\
\hline & & Foundation & 0.458 \\
\multirow{3}{*}{ Building Structure } & Column & 0.221 \\
& \multirow{2}{*}{0.481} & Beam & 0.207 \\
& & Truss & 0.076 \\
& & Stair & 0.039 \\
\hline & Floor & 0.317 \\
& Interior Wall & 0.188 \\
& & External Wall & 0.184 \\
Building Fabric & Roof & 0.121 \\
& & Ceiling & 0.087 \\
& \multirow{2}{*}{0.405} & Door & 0.050 \\
& & Window & 0.031 \\
& & Arch & 0.021 \\
\hline & & Electric & 0.525 \\
Building Service & & Air Condition & 0.279 \\
& & Fire Protection & 0.139 \\
& & Sanitary & 0.057 \\
\hline
\end{tabular}


According to AHP, the element heritage building which is the most important is for is a building structure is a foundation, for building fabric is the floor and for building service is electric. This result is expected because of the fact that all elements in heritage building are important for their function. Arch have lower importance priority weightage from other.

\section{Conclusion}

The element of building selection process in this paper is consider as a part of wider research related to more complex of damage and defect in heritage building. Starting with building defects and associated damage levels, deterioration or damage or is expected to affect its buildings and buildings occupancy is also associated with perceptions and expectations of owners and occupants. Defects or actions required to reduce or eliminate the effects the building will usually be arranged on a pre-determined priority for repairs as inputs obtained from the previous study, the paper focuses on the selection of problem and forecasted attribute element demand in defects.

By considering the selected criteria of building structure, building fabric and building services, various aspects of building elements has been grouped, allowing to choose the right elements of a set of properties. This shown that AHP can be used as a support tool in the decision-making process related to the problem of choosing a heritage building elements, to determine each of the criteria and attributes set out in this research. In the future, these result could be compared with the result obtained by applying some other multi-criteria decision-making approach in order to see a solution to this kind of changes.

This study has been supported by the Office for Research, Innovation, Commercialization and Consultancy Management, University Tun Hussein Onn Malaysia (UTHM), for making this publication possible.

\section{References}

1. S. N. Harun, Heritage building conservation in Malaysia: Experience and challenges. Procedia Engineering, 20, 41-53. (2011).

2. M. A. A. Rahman, Z. A. Akasah \& S. N. F. Zuraidi, An Analysis of Current Demographic Trends of Maintenance Personnel of A Heritage Buildings in Malaysia, International Journal of Advanced Science Engineering Information Technology, Vol.2 (2), (2012).

3. S. N. F. Zuraidi, M. A. A. Rahman, \& Z. A. Akasah, Current Issues and Challenges of the Future In Heritage Building Maintenance at Malaysia: Literature Review, Journal of Humanities, Language, Culture and Business, Vol. 1(4), pp. 13-21 (2017).

4. S. N. F. Zuraidi, M. A. A. Rahman, \& Z. A. Akasah, Elements of building defect: A review of the recent literature, International Annual Symposium on Sustainability Science and Management Proceeding, (2016).

5. S. N. F. Zuraidi, M. A. A. Rahman, \& Z. A. Akasah, Kriteria Penting Untuk Mengukur Keadaan Bangunan Warisan. Malaysian Journal of Social Sciences, Vol. 1(1), 92-102. (2018).

6. S. N. F. Zuraidi, M. A. A. Rahman, \& Z. A. Akasah, Masalah dalam pemuliharaan bangunan warisan di Malaysia. Persidangan Kebangsaan Sains Sosial. (2011).

7. T. L. Saaty, The Analytic Hierarchic Process. New York: McGraw Hill; 1980.

8. A. Pedro, Â. V. Paiva, \& J. Vilhena, Portuguese method for building condition assessment. Structural Survey, Vol. 26(4), pp. 322-335. (2008). 
9. T. L. Saaty, Decision making for leaders - the Analytic Hierarchy Process for decisions in a complex world. Pittsburgh: RWS, (2000).

10. T. L. Saaty, The Analytic Hierarchy and Analytic Network Processes for the Measurement of Intangible Criteria and for Decision-Making. In: Figueira, J, Greco, S, Ehrgott, M, editors. Multiple criteria decision analysis: State of the art surveys, New York: Springer, pp. 345-407. (2005). 